\title{
Graphical User Interface Optimalization Based C\# with Visual Studio to Operator Control Unit Rhino Robot
}

\author{
Tata Tanjung Tamara ${ }^{1}$, Achmad Affandi ${ }^{2}$, Imam Arifin ${ }^{1}$, and M. Fajar Adityo ${ }^{3}$
}

\begin{abstract}
System of communication and data storage on the old version Graphical User Interface (GUI) can not developed or modified because it is not made in a modular way. In addition, the memory capacity is quite large because there are XNA Framework function and excessive robot control menus. Based on these problems we need to optimize GUI on the Operator Control Unit (OCU) Rhino robot. Programming language using C \# with Integrated Development Environment (IDE) Visual Studio. Communication systems and data storage robots are grouped into 3 parts of the program with inheritance class. It creation use one of the IDE features of the Windows Presentation Foundation (WPF). The result of this research is program of communication system and data storage more structured so that can be developed for further research. After that, the memory capacity of the new version of GUI is $57.4 \mathrm{MB}$ with an average memory usage of about 513.5 MB and the number of GUI pages as many as 8 with 3 main page details and 5 supporting pages to control robot motion.
\end{abstract}

Keywords-C\#, GUI, IDE, OCU, WPF, Visual Studio, XNA Framework.

\section{INTRODUCTION}

Rhino robot has arm manipulator and chassis. The chassis part works for robot mobility. While the arm is assigned to take the object considered dangerous. Purpose of this robot was developed to minimize the risk of harm to humans. This robot is controlled by humans remotely with a control device called the Operator Control Unit (OCU).

OCU Rhino robot is shaped like a toughbook laptop that has a Joystick and Graphical User Interface (GUI) with Windows operating system 10. Each serves as a robot controller tool for humans. In Joystick, Robot Control is done using key combinations. Then, users can observe the environment directly and determine the menus of control functions through the GUI.

GUI that has been made there are some problems such as communication systems and data storage robot on the GUI is difficult to develop and modified because it is not made in

${ }^{1}$ Tata Tanjung Tamara and Imam Arifin are with Department of Automation Electrical Engineering, Institut Teknologi Sepuluh Nopember, Surabaya, 60111, Indonesia.

${ }^{2}$ Achmad Affandi is with Department of Electrical Engineering, Institut Teknologi Sepuluh Nopember, Surabaya, 60111, Indonesia. E-mail: affandi@ee.its.ac.id.

${ }^{3}$ M. Fajar Adityo is with Staff of PT Bhimasena Research and Development.

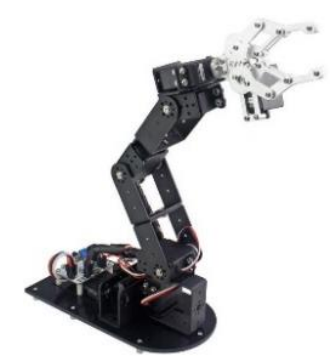

Figure 1. Arm Robot.

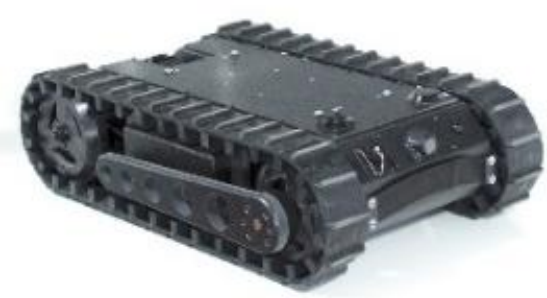

Figure 2. Chasis Robot.

modular. Whereas Rhino robot is still possible to be developed into several versions of different robots. In addition, there are excessive menu controller functions and use one of the features XNA Framework on the GUI. It affects the speed performance when the GUI is run. With these problems need to optimize the GUI on OCU Rhino robot.

In this study, GUI optimization is based on $\mathrm{C} \#$ programming language with Visual Studio's Integrated Development Environment (IDE). Designing the display design and menu layout using one of the features of Visual Studio is Windows Presentation Foundation (WPF). The GUI page is designed to minimize the memory capacity so that the author gives the target an 8-page GUI with details of 3 main pages and 5 pages of support. In the structure of communication programs and data storage robot using inheritance method class or derived class. And the use of this derived class to classify the communication into 3 namely transmitter, receiver and communication center.

\section{RHINO ROBOT, OCU AND GUI}

\section{A. Rhino Robot}

A robot is a mechanical device that can perform physical tasks, either using human control or control, or using pre- 


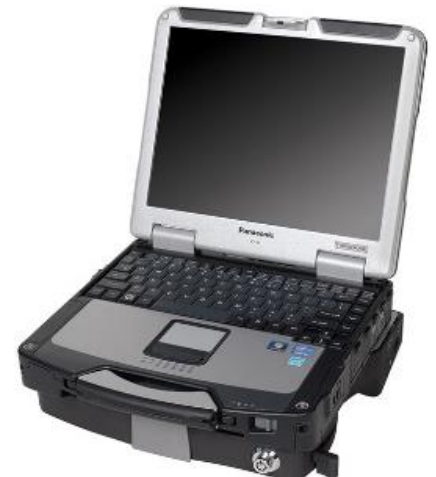

Figure 3. Operator Control Unit (OCU).

defined programs (artificial intelligence) [1]. Advances in robotic technology have made it possible to do things that are usually only done by humans. One of the advancements is the creation of a bomb squad robot. This robot can replace humans to spy on and handle explosives or environmental hazards directly [2]. This object was discovered in 1972 by Lieutenant Colonel Peter Miller by designing electricpowered cart chests to devices such as car bombs so that dangerous objects were safely detonated without injuring anyone [3].

Rhino robot itself consists of 2 main parts of the arm and chassis. In the arm section to take the dangerous object assisted by gripper. This section has 6 Degrees Of Freedom (DoF) can be illustrated as in Figure 1. While the chassis functions for robot mobility. Components in this section consist of several motors, batteries, robot motion support circuits and so on as in Figure 2.

\section{B. $O C U$}

Robots require constant attention and direct control by operators via remote operations called Operator Control Units (OCUs) [4]. Controlling robots through this type of OCU requires full attention by the operator. Operators typically use a joystick type controller to enable various motors on the robot to move it [5]. OCU devices can be illustrated as in Figure 3.

In this study designed an OCU consisting of 3 main parts of Power Distribution, Interface, and GUI. The Power Distribution section is responsible for creating a power supply for the OCU to power up. Then in the Interface section assigned to design the buttons to be integrated by the GUI.

\section{GUI}

The GUI is a pictorial interface for a program to make it easier to use by giving a consistent look like buttons, menus and so on [6]. In addition, it also makes it easy for humans and computers to interact and communicate. This function is usually event-driven which means that some tasks will run every time the event is selected. Such users give inputs on buttons or menu items [7].

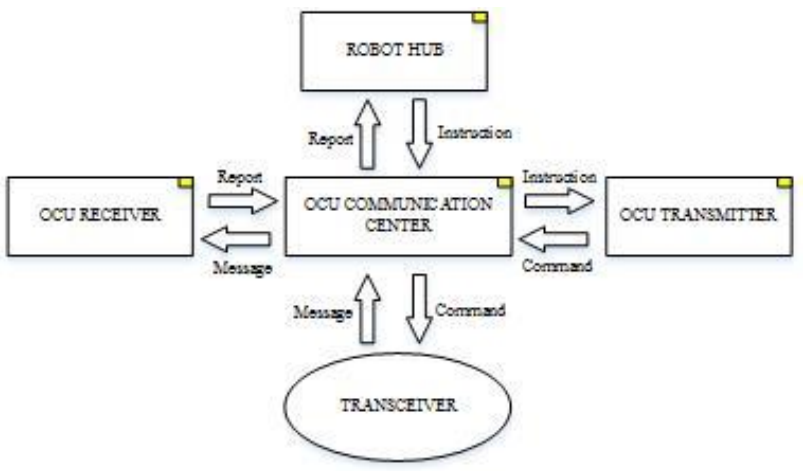

Figure 4. Struktur Sistem Komunikasi dan Penyimpanan Data.

\section{Basic Programming C\#}

C\# (read "See-Sharp") is a multi-purpose computer programming language that is suitable for all developmental needs and object-oriented programs or modern Object Oriented Progamming [8]. OOP is an approach for software development based on objects that interact with each other [9]. Microsoft created $\mathrm{C} \#$ along with the creation of the .NET Framework. C \# promises the productivity and ease of being in Visual Basic with the capabilities and flexibility that exist in $\mathrm{C} / \mathrm{C}++[10]$.

\section{E. WPF}

WPF is a GUI framework that is used to create windows applications just like windows form. This application is a GUI that is used to create client-side applications for windows as well as web-based applications. In addition, it is capable of designing user interfaces with user control [11]. WPF is one of the features in Visual Studio.

WPF is a GUI framework that is used to create windows applications just like windows form. This application is a GUI that is used to create client-side applications for windows as well as web-based applications. In addition, it is capable of designing user interfaces with user control [11]. WPF is one of the features in Visual Studio.

\section{F. Visual Studio}

Is a software that can be used for the development of various applications that have a variety of types including desktop applications (Windows Form, CommandLine, Web Applications, Windows Mobile). This software has more than one compiler ie Visual Basic, C \#, C ++, InterDev, J ++, F \#, Souce Safe and so on [12].

\section{COMMUNICATION SYSTEM, DATA STORAGE AND DISPLAY GUI}

\section{A. Communication System and Data Storage}

Communication and data storage system on the GUI is divided into 5 main parts of Receiver, Transmitter, Communication Center, Robot Hub and Transceiver. The receiver on this system serves as a place of messages sent by 
the Communication Center and prepares reports to be sent to the Communication Center. Then the task of Transmitter is as a place of instruction sent by Communication Center and arrange commands to be sent to Communication Center. Communication Center's own task is to send a report that has

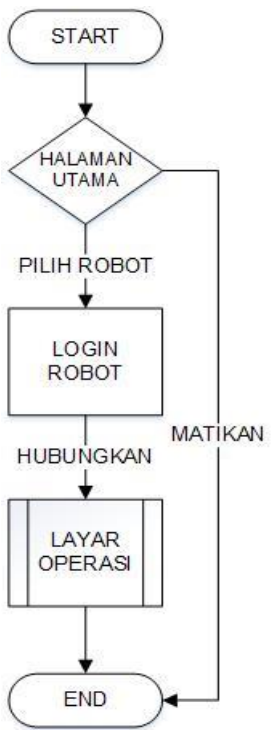

Figure 5. Flowchart GUI's Page (1).

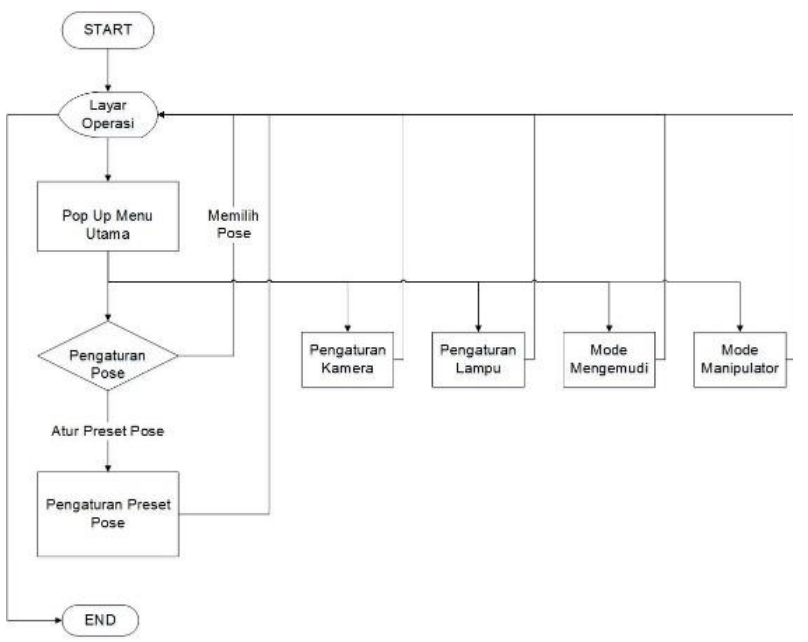

Figure 6. Flowchart GUI's Page (2).

been given by Receiver to Robot Hub, receive instructions from Robot Hub, receive messages from Transmitter and send commands that have been given Transmitter for Transceiver.

\section{B. GUI's Page}

The look and layout of the menu on the GUI plays an important role in controlling and monitoring robots. Therefore, it is necessary to optimize the user interface graphically. Here is the GUI flowchart when run in Figure 5 and Figure 6.

\section{IV.RESULT AND TESTING}

\section{A. Communication system and Data Storage Analysis}

Communication and data storage systems are made in a modular fashion so that there are some differences with the previous system. Here is a comparison of the old GUI system with the new version in Table 1.

TABLE 1.

COMPARATIVE ANALYSIS OF COMMUNICATIONS AND DATA STORAGE SYSTEMS

\begin{tabular}{lll}
\hline \hline \multicolumn{1}{c}{ Information } & \multicolumn{1}{c}{ Old Version } & \multicolumn{1}{c}{ New Version } \\
$\begin{array}{l}\text { Place of } \\
\text { Communication } \\
\text { Data }\end{array}$ & $\begin{array}{l}\text { Communication data } \\
\text { converge on Page }\end{array}$ & $\begin{array}{l}\text { The communication data is } \\
\text { derived according to its } \\
\text { function }\end{array}$ \\
Message data & $\begin{array}{l}\text { Data message is } \\
\text { processed on } \\
\text { RhinoLink }\end{array}$ & $\begin{array}{l}\text { Data message is handled by } \\
\text { OCU Receiver through OCU } \\
\text { Communication Center }\end{array}$ \\
& $\begin{array}{l}\text { Transmitter is on the } \\
\text { page that has direct } \\
\text { access to Transceiver } \\
\text { Robot }\end{array}$ & $\begin{array}{l}\text { Transmitter found on OCU } \\
\text { Transmitter. Access to } \\
\text { Transceiver through OCU } \\
\text { Communication Center first to } \\
\text { be processed then headed to } \\
\text { Transceiver }\end{array}$ \\
& Robot data found on & $\begin{array}{l}\text { Robot data found on RobotHub } \\
\text { RhinoLink }\end{array}$ \\
\hline
\end{tabular}

\section{B. Testing Memory use}

This test is performed to prove the functionality created without using XNA Framework with In Table 2 it explains the memory difference in older versions of GUI with new.

TABLE 2.

COMPARISON OF OLD AND NEW VERSION GUI MEMORY

\begin{tabular}{cccc}
\hline \hline \multirow{2}{*}{ GUI Version } & \multirow{2}{*}{ Size (MB) } & \multicolumn{2}{c}{ Contains } \\
\cline { 3 - 4 } & & Files & Folder \\
\hline Old & 92,8 & 682 & 126 \\
New & 57,4 & 255 & 43 \\
\hline \hline
\end{tabular}

\section{GUI Testing}

Testing the performance of GUI memory speed is intended to find out how much RAM is used. Data is obtained from the Diagnostic Tool on one of the features in Visual Studio. In Table 3. The average GUI calculation is run on equation (1).

TABLE 3.

MEMORY USE DATA

\begin{tabular}{clc}
\hline \hline No & \multicolumn{1}{c}{ Page } & Process Memory (MB) \\
\hline 1 & Start Menu Page & 198 \\
2 & Login Robot & 256 \\
3 & Operation Page & 496 \\
4 & Pop Up Main Menu & 528 \\
5 & Pop Up Pengaturan Pose & 655 \\
6 & Pop Up Preset Pose & 716 \\
7 & Pop Up Pengaturan Kamera & 630 \\
$8 \quad$ Pop Up Ilumination & 629 \\
\hline \hline \multirow{2}{*}{ Average $=\frac{\sum \text { process memory }}{\text { Average }=\frac{4108}{8}}$} & \\
Average $=513,5 \mathrm{MB}$ &
\end{tabular}


International Conference on Engineering, Advance Science and Industrial Application (ICETESIA) 2018 September 6-7 2018, Institut Teknologi Sepuluh Nopember, Surabaya, Indonesia

\section{New Display for GUI New Version}

This test is done so that the created design can be displayed when the GUI is run. In Table 4 is the design of the new GUI menu display and layout. Total number of pages owned is 8 pages with details of 3 main pages and 5 pages of supporters to control the robot and monitor the area.

TABLE 4.

GUI's PAGE DESIGN

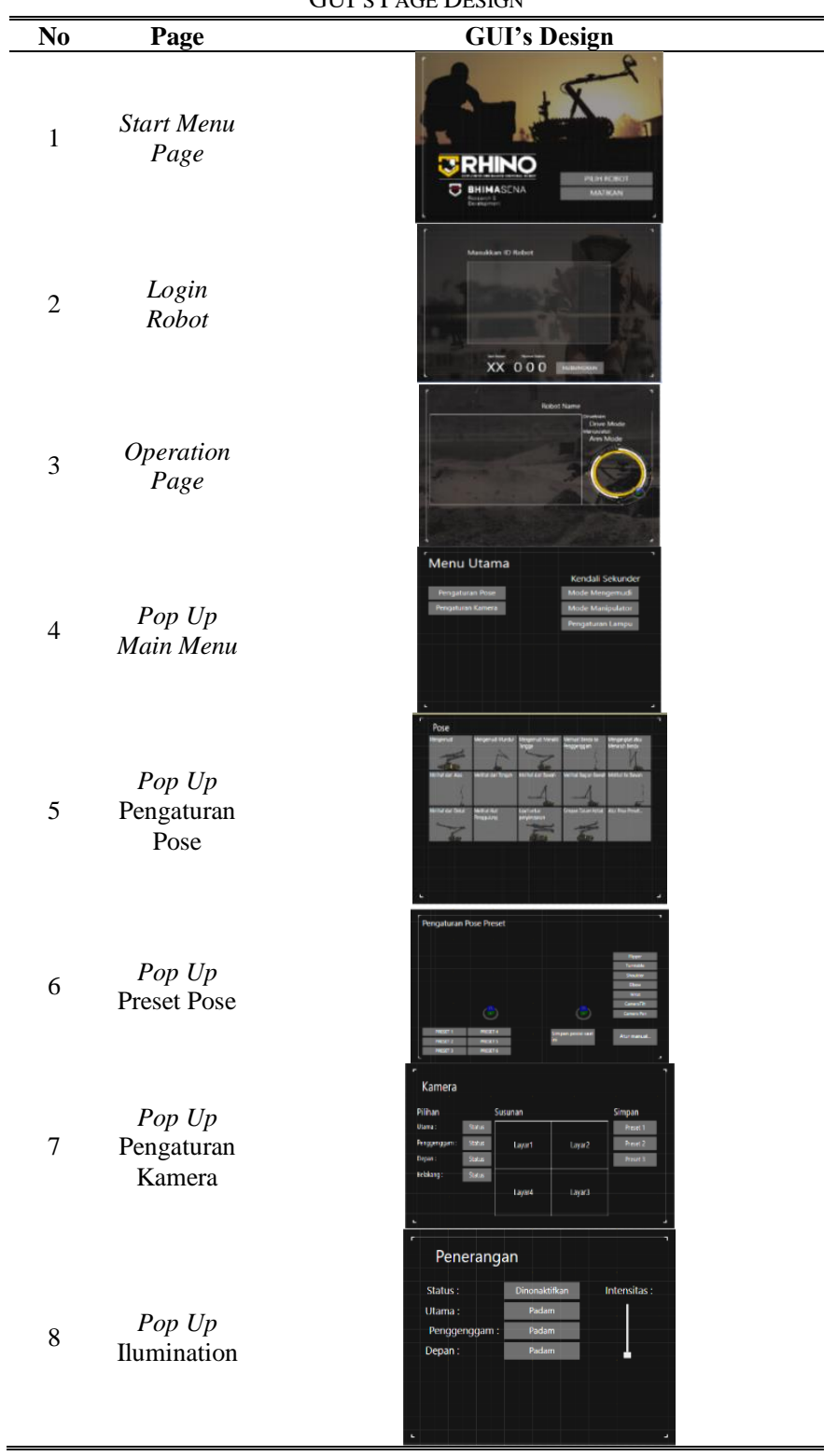

\section{CONCLUSION}

Rhino robot's communications and data storage system in the new version of GUI has been made modular in order to be developed or modified by the next developer. The memory usage generated by the new GUI is $57.4 \mathrm{MB}$ or $38 \%$ lighter than the old-fashioned version of GUI memory of 92.8 MB. Process Memory used by the new version of GUI when running on average uses 513.5 MB. 8-page view and layout design with more compact functionality than previous versions of GUI.

\section{REFERENCES}

[1] A. Nggedho and A. Y. E. Prasetyo, "Prototipe Simulasi Robot Penjinak Bom Dengan Pengendalian Android Berbasis Mikrokontroller Atmega16," Malang.

[2] M. W. Carey, E. M. Kurz, J. D. Matte, T. D. Perrault, and T. Padir, "Novel EOD Robot Design with Dexterous Gripper and Intuitive Teleoperation," Massachusetts, 2012.

[3] "The Very First Bomb Disposal Robot," 2014. [Online]. Available: http://www.military.com/video/ammunition-andexplosives/explosive-ordnance-disposal/the-first-bomb-disposalrobot/3059244734001. [Accessed: 19-Jul-2018].

[4] N. Checka, S. Schaffert, D. Demirdjian, J. Falkowski, and D. H. Grollman, "Handheld operator control unit," Proc. seventh Annu. ACM/IEEE Int. Conf. Human-Robot Interact. - HRI '12, p. 137, 2012.

[5] J. Crossman, R. Marinier, and E. B. Olson, "A hands-off, multirobot display for communicating situation awareness to operators," Proc. 2012 Int. Conf. Collab. Technol. Syst. CTS 2012, pp. 109-116, 2012.

[6] R. Y. Al Ashi and A. Al Ameri, "Introduction to Graphical User Interface (GUI) MATLAB 6.5," IEEE UAEU Student Branch UAE Univ., pp. 1-35, 2004.

[7] W. L. Martinez, "Graphical user interfaces," Wiley Interdiscip. Rev. Comput. Stat., vol. 3, no. 2, pp. 119-133, 2011.

[8] A. Hejlsberg, "C Sharp Programming Language," p. 704, 2006.

[9] D. Clark, "Beginning C \# Object Oriented Programming, 2nd Ed.," p. 373, 2013.

[10] A. Rachmatullah, "Mempelajari C\#: Bahasa Pemrograman Modern," pp. 1-136, 2002.

[11] A. Misra, "Use of Windows Presentation Foundation and Windows Forms in Windows Application Programming," vol. 7, no. 7, pp. 20-24, 2016.

[12] R. Yesputra, Belajar Visual Basic . Net dengan Visual Studio 2010, no. October. 2017. 